\title{
The ophthalmic science behind eyeblack grease and its use in professional and youth athletics
}

\begin{abstract}
Athletic performance is affected by glare and contrast sensitivity. There are currently multiple methods to reduce glare during conditions of sunlight and stadium lighting. Various methods are reviewed including the historical development, effectiveness, and scientific benefits of EyeBlack grease and stickers. A review of the historical publications and media coverage of EyeBlack is outlined in context to its perceived and proven attributes.
\end{abstract}

Keywords: glare, contrast sensivity, eyeblack grease, eyeblack stickers, sports ophthalmology, psychological war paint
Volume 4 Issue 2 - 2016

\author{
Brian M DeBroff \\ Department of Ophthalmology and Visual Science, Yale \\ University School of Medicine, USA
}

\begin{abstract}
Correspondence: Brian M DeBroff,Associate Clinical Professor, Yale University School of Medicine, Ophthalmology Surgical Services, Department of Veterans Affairs, West Haven 950 Campbell Avenue, West Haven, CT 06516, USA, Tel (203) 785-1755, Email bmdmd@aol.com
\end{abstract}

Received: January 10, 2016 | Published: February 17, 2016

\section{Introduction}

Scattering of light can produce glare which, in turn, can lead to visual disability. Athletes are particularly challenged by glare and athletic performance is influenced by the athlete's visual function. Contrast sensitivity, defined as the ability to detect the presence of minimal luminance differences between objects, ${ }^{1}$ is useful to all players because it helps athletes distinguish objects from their backgrounds. Laby tested binocular contrast sensitivity in 387 professional baseball players and demonstrated that athletes had greater contrast sensitivity. ${ }^{2}$ In another study of athletes, Kluka found that the higher the athlete's contrast sensitivity, the more likely the athlete can discriminate an object as its velocity increases. ${ }^{3}$ Campbell found that batter reaction times to pitches are slower in low light levels. ${ }^{4-6}$ Glare impairs an athlete's contrast sensitivity. There are currently a variety of glare reducing products to improve contrast sensitivity and performance in conditions of disabling glare, however, many of these items have not been proven effective in clinical studies and have known limitations. For example, visors do not protect against reflected light and can reduce ocular exposure by half. Sunglasses lower background illumination and can diminish visual acuity. Polarized sunglasses can transmit a maximum of $50 \%$ of normal unpolarized light. ${ }^{7}$ Tinted filters selectively absorb specific color wavelengths of light, but by selectively inhibiting certain wavelengths can be detrimental to some visual tasks. Because of the above limitations, athletes have been turning to alternatives, like EyeBlack, to improve vision during sports activities in conditions of bright light.

EyeBlack is typically black grease that is applied to the cheekbone region under each eye to absorb sunlight or stadium lights and reduce light waves reflecting through the pupils. EyeBlack grease is made from a mixture of beeswax, paraffin, and carbon; stickers are made from patented fabric. This mimics the natural masks found in animals such as wolves, badgers, and even killer whales. ${ }^{89}$ Professional baseball, football, and lacrosse players have been using EyeBlack for decades and athletes in other sports are joining the ranks. The earliest report of EyeBlack use was in1904 when an article in Sporting Life reported that Pat Dougherty of the Boston Red Sox "rubs mud or charcoal under his eyes." 10 In 1905, another article in the Sporting Life reported that Sandow Mertes of the New York Giants tried the trick of painting black around the eyes instead of wearing smoked glasses. ${ }^{10}$ It is interesting to note that Mertes misjudged a fly ball and let in the winning run in that game. The first photographic evidence of EyeBlack's use is found in a 1942 photograph of Washington Redskins football player Andy Farkas in a game against the Philadelphia Eagles. Perhaps this is what led "Anvil Andy" Farkas to become a top NFL scorer, and the recipient of the first 99 yard touchdown pass. His grandson, Brian Farkas, is founder and CEO of one of the leading EyeBlack companies, Farkas EyeBlack and is carrying on Andy Farkas' legacy.

Evidence from the 1940's suggests that players used to burn cork and then smear the ashes on their cheeks [8]. By the late1940's EyeBlack started becoming popular with professional football players and by early 2000, players were starting to wear EyeBlack stickers with Bible verses and encrypted messages. ${ }^{10}$ Reggie Bush famously adorned his cheekbones with "619" (his home area code) and "SE" (his hometown's southeastern location). ${ }^{11}$ College football players began wearing their school logo, including Texas, Ohio State, UCLA, and UConn. Khalil Jones is credited with the first player to wear his EyeBlack logo upside down. Andrew Jones of the Atlanta Braves was the first to wear just one Eyeblack sticker under his left eye. Later, other athletes such as Bryce Harper and Ray Lewis would smear EyeBlack more than halfway down their cheeks.

The actual effectiveness of EyeBlack has been a constant source of debate, in part because no actual trials have ever been done in its decades long history. Mueller Sports Medicine had been selling it for nearly 40 years with only non-controlled and non- published studies which reportedly showed reduced reflection of laser beams off of sticker material. ${ }^{8}$ EyeBlack has become a sports accessory, with players donning it during night games and indoor games. Athletes use it for the competitive edge, an aggressive look and an extra psychological advantage. 
In 2001, ophthalmologists Dr. Brian DeBroff (author) and Dr. Patty Pahk of the Yale University School of Medicine performed a randomized, controlled study to determine if glare reducing products such as EyeBlack grease and No Glare stickers marketed to athletes for reduction of glare actually improve contrast sensitivity during sunlight exposure. Their initial hypothesis was that EyeBlack was mainly psychological war paint with no real visual benefit. The subjects were randomized to one of three treatment groups (EyeBlack grease, No Glare stickers and Vaseline placebo). To the surprise of the investigators, the study found that EyeBlack reduced glare from the sun and improved contrast sensitivity, whereas, commercial antiglare stickers and the control were ineffective. Results of the study were first presented at the Association for Research in Vision and Ophthalmology annual meeting on December $1,2001 .{ }^{12}$ The scientific study was published in Archives of Ophthalmology in 2003 by DeBroff and Pahk ${ }^{13}$ and Dr. Pahk's thesis of the "Ability of Periorbitally Applied Anti-Glare Products to Improve Contrast Sensitivity in Conditions of Sunlight Exposure" was accepted as her graduating thesis from the Yale University School of Medicine's Class of 2002. ${ }^{14}$

After publication of the study, the Los Angeles Times declared "the dark rings are de rigueur in sports such as football and baseball." ${ }^{15}$ The New York Times Science Editor, Eric Nagouney conluded: "It looks scary, and it works." ${ }^{16}$ Science News declared "Antiglare EyeBlack is better than tape. ${ }^{17}$ In 2005, Benjamin R. Powers at the University of New Hampshire performed a similar study and confirmed EyeBlack reduced glare and improved contrast sensitivity. ${ }^{18}$ In 2011, after Cardinal's first baseman Albert Pujols publically complained about shadows and visibility at Busch Stadium during the World Series, DeBroff mailed him a tin of Farkas Eye Black and a copy of the EyeBlack study. No reply was forthcoming. In 2015, on Discovery Channel's Myth busters, Savage and Hyneman, found that while EyeBlack may not completely eliminate glare, it does improve an athlete's ability to differentiate between light and dark. ${ }^{19}$

The author published the book: The Eye Black Study in 2013 with profits going toward the Prevent Blindness program of Distressed Children International. EyeBlack grease has become popular as a method to improve contrast sensitivity. Most athletes, however, also claim the very important aspects of aggressive appearance and psychological war paint mentality for their use of EyeBlack grease. In 2015, ESPN aired a segment regarding the current use of EyeBlack grease which included an interview with DeBroff. ${ }^{20}$ The overriding message conveyed in the ESPN segment was that athletes like the look and psychological advantage of EyeBlack grease. The concensus is that, yes, EyeBlack does reduce glare on a bright day, but the little league world series players described the visual benefits as "having nothing to do with it." Walker Lannom, a little league player from of Bonita, CA stated that when he puts it on, it makes him "intimidating and scarier." Bryce Harper of the Washington Nationals stated in the clip "I love it and would use it even if it was a cloudy day... I have to have it!" EyeBlack remains popular today for its intimidating factor and psychological advantages, but as professional athletes often serve as role models for today's youth, parents can at least be comforted by the fact that there is scientific validation of a visual benefit to EyeBlack grease. It is not often that a product not only looks good, but is good for you. I think Jones, Bush, Harper, and yes even Andy Farkas would agree.

\section{Acknowledgments}

None.

\section{Conflicts of interest}

The author is Scientific Advisor to Farkas Eye Black, Inc and is on the Board of Directors for Farkas Eye Black, Inc which was founded in 2000; any and all compensation has been donated to Dr. DeBroff's nonprofit organization: Distressed Children and Infants International.

\section{Funding}

None.

\section{References}

1. Prager TC. Essential Factors in Testing for Glare. In: Glare and Contras Sensitivity for Clinicians. In: MP Nadler, D Miller, DJ Nadler, editors. New York: Springer-Verlag, Inc. USA; 1990; p. 33-44.

2. Laby DM, Rosenbaum AL, Kirschen DG, et al. The visual function of professional baseball players. Am J Ophthalmology. 1996;122(4):476485 .

3. Kluka DA, Love PL, Kuhlman J, et al. The effect of a visual skills training program on selected collegiate volleyball athletes. International Journal of Sports Vision. 1996;3(1):23-34.

4. Campbell FW, Rothwell SE, Perry MJ. Bad light stops play. Ophthalmic and Physiological Optics. 1987;7(2):165-167.

5. Perry MJ, Campbell FW, Rothwell SE. A physiological phenomenon and its implications for lighting design. Lighting Research and Technology. $1987 ; 19(1): 1-5$.

6. Rothwell SE, Campbell FW. The physiological basis for the sensation of gloom: quantitative and qualitative aspects. Ophthalmic Physiol Opt. 1987;7(2):161-163.

7. Chatman WN, MacEwen CJ. Light and lighting. In: Sports Vision. In: DFC Loran, CJ MacEwen, editors. Oxford: Butterworth-Heinemann Ltd. USA; 1995. p. 88-112.

8. Bryce R. Out of left field. 2001

9. Glareblox stick on strips product website.

10. Rushin S. The 34-Ton Bat \& 375 Other Strange \& Unforgettable Objects. 1st ed. Little, Brown and Company, New York, NY, USA; 2013. p. 145 148 .

11. Lukas P. The Evolution of Eye Black. Uni Watch, Sports. ESPN.go.com, lukas/061127. 2008.

12. DeBroff BM, Pahk PJ. Ability of periorbitally applied anti-glare products to improve contrast sensitivity in conditions of sunlight exposure. Investigative Ophthalmology and Visual Science. 2002;43(suppl):851.

13. DeBroff BM, Pahk PJ. The ability of periorbitally applied antiglare products to improve contrast sensitivity in conditions of sunlight exposure. Arch Ophthalmol. 2003;121(7):997-1001.

14. Pahk PJ. Ability of periorbitally applied anti-glare products to improve contrast sensitivity in conditions of sunlight exposure. Yale University Press; 2002. p. 1-45.

15. Jameson M. The eyes have it: Study shows glare-busting grease works. LA Times, Fitness Section. 2003. 
16. Nagourney E. Field of vision: It looks scary, and it works. NY Times, Science Section. Science News. 2003;164(5):77.

17. Powrs B. Why do Athletes Use Eye Black? University of New Hampshire Inquiry Journal. 2005.
18. Savage A, Hyneman J. Baseballs Player's Eye Black Cuts Out Glare, Discovery Channel Mythbusters. 2015.

19. Abrams B. Eye black a statement for Harper, Little League World Series players, espn.go.com. 2015;3:18. 